\title{
ANALISIS WEB USAGE MINING MENGGUNAKAN METODE MODIFIED GUSTAFSON - KESSEL CLUSTERING DAN ASSOCIATION RULE PADA WEBSITE UNIVERSITAS DIPONEGORO
}

\author{
Galuh Nurvinda Kurniawati ${ }^{1}$, Rukun Santoso ${ }^{2}$, Sugito $^{3}$ \\ 1,2,3 Departemen Statistika, Fakultas Sains dan Matematika, Universitas Diponegoro \\ galuhnurvinda@gmail.com
}

\begin{abstract}
The comprehension of web visitors patterns are needed to develop website in an optimal fashion. The visitor pattern contained in the web log file ofDiponegoro University's website is clustered by Modified GustafsonKessel method. In general, this method produces two until six clusters. Two kinds of results are outlined in this paper. The first is the result contains two clusters, and the second is containing three clusters. In the first result, the visitors are divided into information seekers of student capacity and Engineering Faculty. In the second result, the visitors are divided into information seekers of Medicine Faculty, student admission and Engineering Faculty.
\end{abstract}

Keywords: website, web usage mining, web log file, Modified Gustafson-Kessel Clustering, Association Rule

\section{PENDAhULUAN}

Di era modern saat ini, perkembangan teknologi sangat pesat, khususnya teknologi yang berhubungan dengan internet yang semakin mudah diakses.Perkembangan internet berbanding lurus dengan pemanfaatan website dalam berbagai bidang. Seiring dengan meningkatnya pemanfaatan website, aktivitas user dalam penggunaan website pun semakin meningkat.Semakin banyak aktivitas user dalam laman website menghasilkan data server log-file yang besar mengenai riwayat interaksi user yang tersimpan di dalam web log server.Web mining adalah teknik untuk mengolah data server log-file dari website.Web mining dibagi menjadi tiga jenis yaitu, web structure mining, web content mining, dan web usage mining. Web usage mining adalah teknik untuk menemukan pola atau pattern dari user dalam mengakses web ${ }^{[4]}$.

Clustering adalah pengelompokan data berdasarkan karakteristik umum ${ }^{[5]}$. Gustafson-Kessel Clustering merupakan pengembangan dari Fuzzy C-Means dengan mengasosiasikan setiap cluster dengan pusat cluster dan matriks kovariannya untuk memperoleh jumlah cluster optimum menggunakan nilai partition coefficient dan coefficient entropy. Hasil akhir penelitian ini adalah pengelompokan user yang memiliki kemiripan pola navigasi untuk memahami tingkah laku user dalam mengakses website sehingga hasil dari penelitian ini dapat digunakan sebagai acuan dalam perbaikan kualitas website dan mengoptimalkan fitur-fitur yang tersedia di website.

\section{TINJAUANPUSTAKA}

\subsection{Web Mining dan Web Usage Mining}

Pengambilan data website menggunakan teknik data mining disebut dengan web mining.Web mining mempermudah pencarian informasi termasuk penemuan dan analisis data, dokumen serta multimedia karena berhubungan dengan World Wide Web. Web mining dibedakan menjadi tiga jenis yaitu, Web Structure Mining, Web Content Mining, dan Web Usage Mining ${ }^{[6]}$.

Data pola penggunaan (usage pattern) dan aktivitas user website dapat diproses menggunakan metode web usage mining. Data tersebut merupakan server log-file.Server 
log-file mengumpulkan berbagai data tentang permintaan (request) informasi ke server web. Berikut ini merupakan contohserver log-file

37.9.113.49 - - [01/Nov/2019:03:25:04 +0700] "GET /language/id/penerimaanmahasiswa-baru/daya-tampung?lang=id HTTP/1.1" $200 \quad 88736 \quad$ "-" "Mozilla/5.0 (compatible; YandexBot/3.0; +http://yandex.com/bots)" "-"

\subsection{Preprocessing}

Tujuan preprocessing adalah untuk mendapatkan data pengguna mentah dari serangkaian request yang dicatat dalam bentuk server log-file ${ }^{[2]}$.Secara singkat preprocessing dilakukan dengan maksud untuk:

a. Cleaning data, yaitu memfilter data yang tidak di-request oleh user. Data ini terjadi karena adanya automatic request.

b. Menyingkirkan aktivitas yang dilakukan oleh bot yang dianggap tidak memiliki informasi yang berguna berkaitan dengan web usage mining.

c. Identifikasi user menggunakan alamat IP sebagai identitas unik dari tiap user.

d. Indentifikasi usersession, yaitu menentukan halaman-halaman yang di-request untuk setiap kunjungan user.

e. Indentifikasi kategori, yaitu mengelompokkan request sub halaman yang bisa digabung.

\subsection{Translation}

Pada tahap ini datapage requestberbahasa Inggris akan diubah menjadi bahasa Indonesia agar session yang bermakna sama tidak terhitung dua kali.

\subsection{Text Representation}

Text representation bertujuan untuk secara numeric mewakili teks yang tidak terstruktur agar dapat dihitung secara matematis ${ }^{[7]}$. Setelah server log-file melewati prosesproses sebelumnya, maka data telah siap direpresentasikan menjadi bentuk document term matrix.Matriks berisi frekuensi page request yang muncul (TF) dan pembobotan menggunakan pembobotan TF-IDF.Algoritma pembobotan TF-IDF terdiri dari dua term yaitu:

a. Term Frequency (TF), yaitu jumlah page request yang ingin diboboti dibagi dengan jumlah total page request yang diakses oleh satu user. Semakin besar jumlah kemunculan suatu page request maka semakin besar pula bobot yang diberikan.

b. nvers Document Frequency (IDF) merupakan hasil log dari jumlah total user yang merequest page request dibagi dengan jumlah seluruh user

Rumus umum pembobotan TF-IDF sebagai berikut

dengan:

$$
W_{j, i}=\frac{n_{j, i}}{\sum_{j=1}^{p} n_{j, i}} \cdot \log _{2} \frac{D}{d_{i}}
$$

$W_{j, i} \quad:$ pembobotan TF-IDF untuk page request ke-j pada dokumen ke-i.

$n_{j, i} \quad:$ jumlah kemunculan page request ke-j pada dokumen ke-i.

$\sum_{j=1}^{p} n_{j, i} \quad:$ jumlah kemunculan seluruh page request pada dokumen ke-i.

$D \quad$ : banyaknya dokumen yang dibangkitkan

$d_{i} \quad$ : banyaknya dokumen yang mengandung page request ke-i.

$\mathrm{p} \quad$ : banyaknya page request yang terbentuk 


\subsection{Modified Gustafson - Kessel Clustering}

Algoritma Gustafson-Kessel mengubah fungsi perhitungan jarak menjadi fungsi jarak adaptif (adaptive distance norm) yang selalu diperbaharui pada setiap iterasi dengan menggunakan matriks fuzzy covariance ${ }^{[3]}$. Algortima Gustafson-Kessel menggunakan fungsi jarak mahalanobis sehingga lebih dapat menyesuaikan bentuk geometris untuk sebuah himpunan data, tidak seperti Fuzzy C-Means yang mengasumsikan bahwa bentuk gemoetris suatu cluster adalah bulat sempurna.Meskipun Gustafson-Kessel lebih unggul dari algoritma Fuzzy C-Means, masih terdapat masalah saat matriks fuzzy covariance dari data merupakan matriks singular maka perhitungan matriks $\boldsymbol{A}_{\boldsymbol{k}}$ tidak dapat diterapkan.

Algoritma modified Gustafson-Kessel Clustering secara lengkap adalah sebagai berikut $^{[1]}$ : input data yang akan dikelompokkan sebagai $\mathrm{X}$ (matriks a $\mathrm{x}$ b), menentukan jumlah cluster yang akan dibentuk $(\mathrm{c} \geq 2)$, weighting exponent $(\mathrm{m}>1)$, maksimum iterasi $\left(\mathrm{t}_{\max }\right)$, error terkecil yang diharapkan $(\varepsilon)$, nilai threshold $(\beta)$, dan parameter pembobot $\gamma \in$ [0,1]. Membangkitkan bilangan random $u_{i k}, 1 \leq i \leq \mathrm{n} ; 1 \leq k \leq \mathrm{c}$ sebagai elemen - elemen matriks partisi awal $\boldsymbol{U}_{\boldsymbol{0}}$ dan hitung matriks kovarian $\boldsymbol{F}_{\boldsymbol{0}}$ dari keseluruhan data.

$$
\sum_{k=1}^{c} u_{i k}^{m}=1,1 \leq i \leq \mathrm{n} ; 1 \leq k \leq \mathrm{c}
$$

Lalu dilanjutkan untuk $t=1,2, \ldots, t_{\max }$

Step 1.menghitung pusat cluster ke-k $\left(v_{k}\right)$ dengan rumus:

dengan:

$$
v_{k}^{(t)}=\frac{\sum_{i=1}^{n}\left(u_{i k}^{(t-1)}\right)^{m} x_{i}}{\sum_{i=1}^{n}\left(u_{i k}^{(t-1)}\right)^{m}}, 1 \leq k \leq \mathrm{c}
$$

$$
\begin{array}{ll}
u_{i k} & =\text { derajat keanggotaan dari data ke-i pada } c \text { luster ke-k } \\
\mathrm{m} & =\text { pangkat pembobot untuk fungsi keanggotaan fuzzy } \\
\mathrm{t} & =\text { banyaknya iterasi } \\
\mathrm{n} & =\text { banyaknya data } \\
\mathrm{c} & =\text { banyaknya cluster }
\end{array}
$$

Step 2. Menghitung matriks kovarian cluster dengan rumus:

dengan:

$$
\boldsymbol{F}_{\boldsymbol{k}}=\frac{\sum_{i=1}^{n}\left(u_{i k}^{(t-1)}\right)^{m}\left(x_{i}-v_{k}^{(t)}\right)\left(x_{i}-v_{k}^{(t)}\right)^{T}}{\sum_{i=1}^{n}\left(u_{i k}^{(t-1)}\right)^{m}}
$$

$\boldsymbol{x}_{\boldsymbol{i}}=$ vektor data ke-i

$\boldsymbol{v}_{\boldsymbol{k}}=$ pusat cluster $\mathrm{ke}-\mathrm{k}$

$\mathrm{u}_{\mathrm{ik}}=$ derajat keanggotaan data ke-i pada cluster $\mathrm{ke}-\mathrm{k}$

$m=$ pangkat pembobot untuk fungsi keanggotaan fuzzy

$t=$ banyaknya iterasi

$n=$ banyaknya data

$c=$ banyaknya cluster

Ekstraksi nilai eigenvactors $(\phi)$ dan eigenvalues $(\lambda)$ dan menghitung nilai

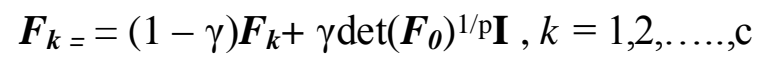

dengan:

$\gamma=$ parameter untuk mengatur bentuk matriks fuzzycovariance, $\gamma \in[0,1]$

$\boldsymbol{F}_{\boldsymbol{0}} \quad=$ matriks kovarian dari seluruh data

$\boldsymbol{F}_{\boldsymbol{k}} \quad=$ matriks fuzzy covariance cluster $\mathrm{ke}-\mathrm{k}$ (pada persamaan 4)

$p \quad=$ banyaknya variabel

I = matriks indentitas 
Jika rasio antara nilai eigen maksimal dan minimal melewati nilai threshold yang ditentukan, maka rekonstruksi $\boldsymbol{F}_{\boldsymbol{k}}$ dengan penjabaran sebagai berikut:

$$
\boldsymbol{F}_{\boldsymbol{k}}=\boldsymbol{\phi} \boldsymbol{\Lambda} \boldsymbol{\phi}^{-1}, k=1,2, \ldots, \mathrm{c}
$$

dengan:

$\boldsymbol{\phi}=$ vektor eigen dari matriks fuzzy covariance cluster $\mathrm{ke}-\mathrm{k}$

$\boldsymbol{\Lambda}=$ matriks diagonal dari nilai-nilai eigen (eigen values) matriks fuzzy covariance cluster ke-k

Step 3. Menghitung jarak dengan persamaan (3) dari norm inducing matrix di persamaan (5) dengan $i=1,2, \ldots, \mathrm{n}$ dan $k=1,2, \ldots$, c. sehingga didapat:

$$
D_{i k A \mathrm{k}}^{2}=\left(x_{i}-v_{k}^{(t)}\right)^{T}\left[\rho_{k} \operatorname{det}\left(\boldsymbol{F}_{\boldsymbol{k}}\right)^{\frac{1}{p}} \boldsymbol{F}_{\boldsymbol{k}}^{-1}\right]\left(x_{i}-v_{k}^{(t)}\right)
$$

dengan:

$D_{i k A \mathrm{k}}^{2}$ : jarak data ke-i terhadap pusat cluster dengan normincluding matrix $\boldsymbol{A}_{\mathrm{k}}$

$\boldsymbol{x}_{\boldsymbol{i}} \quad$ : vektor data ke-i

$v_{k} \quad$ : pusat cluster ke-k

$\boldsymbol{F}_{\boldsymbol{k}} \quad$ : matriks fuzzy covarian cluster ke-k

$\rho_{k} \quad$ : volume cluster ke-k

$p \quad$ : banyaknya variabel

n : banyaknya data

c : banyaknya cluster

Step 4. Memperbarui matriks fungsi keangotaan

Untuk $1 \leq i \leq n$

Jika $D_{i k A \mathrm{k}}^{2}>0$ untuk $1 \leq k \leq c$

$$
u_{i k}^{(t)}=\left[\sum_{l=1}^{c}\left(\frac{D_{i k A_{\boldsymbol{k}}}}{D_{i l A_{\boldsymbol{k}}}}\right)^{\frac{2}{(m-1)}}\right]^{-1}
$$

Jika tidak, maka:

$$
\begin{gathered}
u_{i k}^{(t)}=\underset{j \mathrm{jika} D_{i k A \mathrm{k}}^{2}>0 \text { dan }}{\operatorname{dengan} \sum_{k=1}^{c} u_{i k}^{(t)} \in[0,1]} \\
\underset{i k}{(t)}=1
\end{gathered}
$$

Iterasi dihentikan jika $\left\|\boldsymbol{U}^{(\mathrm{t})}-\boldsymbol{U}^{(\mathrm{t}-1)}\right\|<\varepsilon$ atau jika $t>$ iterasi maksimum.

Nilai threshold $(\beta)$ yang digunakan biasanya ditentukan dalam angka yang besar, seperti $10^{15}$.

\subsection{Association Rule}

Association rule mining adalah teknik data mining untuk menemukan aturan asosiatif antara suatu kombinasi item. Ada dua parameter untuk mengetahui penting atau tidaknya suatu aturan asosiasi yaitu support (nilai penunjang) dan confidence (nilai kepastian). Analisis asosiasi terbagi menjadi dua tahap:

a. Analisis pola frekuensi tinggi

Nilai support sebuah item diperoleh dengan rumus sebagai berikut:

$$
\operatorname{Support}(\mathrm{A})=\frac{\sum \text { transaksi yang mengandung item } A}{\text { total transaksi }}
$$

Sedangkan nilai support dari 2 item adalah sebagai berikut:

$$
\text { Support }(\mathrm{A} \cap B)=\frac{\text { Stransaksi yang mengandung item } A \text { dan } B}{\text { total transaksi }}
$$

b. Pembentukan aturan asosiatif

Nilai confidence dari aturan $\mathrm{A} \rightarrow \mathrm{B}$ diperoleh dari rumus berikut:

$$
\mathrm{P}(\mathrm{B} \mid \mathrm{A})=\frac{\sum \text { transaksi yang mengandung item } \mathrm{A} \text { dan } B}{\text { total transaksi } A}
$$


Pada bahasa pemrograman $\mathrm{R}$, terdapat variable lift, yaitu pengukuran independensi dari A dan B. Nilai lift antara 0 hingga tak hingga.Sehingga rule yang dapat digunakan adalah yang hanya memiliki nilai lift $>1$.

$$
\text { Lift }=\frac{P(B \mid A)}{P(A) P(B)}
$$

Nilai lift $=1$, artinya A dan B adalah independen

Nilai lift $<1$, artinya B tidak cenderung terjadi terhadap A

Nilai lift $>1$, artinya B lebih cenderung terjadi terhadap A

\section{METODE PENELITIAN}

Data yang digunakan dalam penelitian ini merupakan data primer yang didapat dari data web log serverwebsite Universitas Diponegoro (www.undip.ac.id) yang hanya bisa diakses oleh admin pada tanggal 1 November 2019 hingga 7 November 2019. Analisis pengelompokkan menggunakan metode Gustafson-Kessel Clustering menggunakan software Matlab 2016a dan dilanjutkan dengan Association rule untuk mengetahui pola user menggunakan software Rstudio. Proses text representation untuk membentuk matriks TF-IDF dan tokenizing menggunakan software Rstudio.

\section{HASIL DAN PEMBAHASAN}

Web log yang dianalisis adalah records dari tanggal 1 November 2019 hingga 7 November 2019. Data tersebut terdiri dari 6500 page request dengan jumlah IP Address sebanyak 2496.

\subsection{Preprocessing}

Preprocessing merupakan proses untuk mempersiapkan data agar data bisa diolah lebih lanjut. Langkah - langkah preprocessing adalah data cleansing, menyingkirkan aktivitas bot, Mengidentifikasi user menggunakan alamat IP sebagai identitas unik, mengidentifikasi user session, dan mengidentifikasi kategori. Contoh preprocessing terlihat pada Tabel 1 .

Tabel 1. Contoh Preprocessing

\begin{tabular}{cccc}
\hline No. & Alamat IP & Kode Alamat IP & Page Request \\
\hline 1. & 125.163 .220 .242 & 10 & fakultas/fakultas-teknik/ fakultas/ \\
2. & 114.125 .52 .228 & 24 & beasiswa-bidikmisi/ beasiswa-bidikmisi/ \\
\hline
\end{tabular}

\subsection{Translation}

Pada proses translationpage request berbahasa Inggris diterjemahkan mejadi bahasa Indonesia agar session yang bermakna sama tidak terhitung dua kali. Pada Tabel 2 terlihat kata 'leaders' berubah menjadi 'pimpinan' dan 'academic-regulations' berubah menjadi 'peraturan-akademik'.

Tabel 2. Contoh Translation

\begin{tabular}{cccc}
\hline No. & kode & Sebelum Translation & Setelah Translation \\
\hline 1. & 28 & profil/leaders/ & profil/pimpinan/ \\
2. & 60 & academic-regulations/ & peraturan-akademik/ \\
\hline
\end{tabular}

\subsection{Text Representation}

Proses ini bertujuan untuk mengetahui page requestyang di-request oleh seorang user secara keseluruhan dari tanggal 1 November 2019 hingga 7 November 2019 dan dibentuk menjadi Documen Term Matrixmenggunakan pembobotan TF-IDF dengan fungsi 'as . matrix (weightTfIdf(m=DocumentTermMatrix (data), normalize=TRUE))'. 
Berdasarkan hasil text representation, dari total 6500 page request ternyata hanya disusun oleh 94 page request. Artinya, satu page request dapat di-request lebih dari satu kalioleh user.Contoh matriks TF dan matriks IDFterlihat pada Tabel 3dan Tabel 4.

Tabel 3. Contoh Matriks TF

\begin{tabular}{c|c|ccc}
\hline \multirow{2}{*}{$\begin{array}{c}\text { Kode } \\
\text { user }\end{array}$} & Gabungan Page request & \multicolumn{3}{|c}{ Page request } \\
\cline { 3 - 5 } & $\begin{array}{c}\text { fakultas/fakultas- } \\
\text { ilmu-budaya/ }\end{array}$ & fakultas/ & $\begin{array}{c}\text { fakultas/fakultas- } \\
\text { psikologi/ }\end{array}$ \\
\hline 13 & $\begin{array}{c}\text { fakultas/fakultas-ilmu- } \\
\text { budaya/ fakultas/ } \\
527\end{array}$ & 1 & 2 & 0 \\
fakultas/fakultas-psikologi/ & 0 & 0 & 1 \\
\hline
\end{tabular}

Tabel 4. Contoh Matriks TF-IDF

\begin{tabular}{c|c|ccc}
\hline \multirow{2}{*}{$\begin{array}{c}\text { Kode } \\
\text { user }\end{array}$} & Gabungan Page request & \multicolumn{3}{|c}{ Page request } \\
\cline { 3 - 5 } & $\begin{array}{c}\text { fakultas/fakultas- } \\
\text { ilmu-budaya/ }\end{array}$ & fakultas/ & $\begin{array}{c}\text { fakultas/fakultas- } \\
\text { psikologi/ }\end{array}$ \\
\hline 13 & $\begin{array}{c}\text { fakultas/fakultas-ilmu- } \\
\text { budaya/ fakultas/ } \\
527\end{array}$ & 1,6485 & 0,9747 & 0 \\
fakultas/fakultas-psikologi/ & 0 & 0 & 4,9279 \\
\hline
\end{tabular}

\subsection{Pe ngaplikasian Algortima Gustafson-Kessel Clustering}

Clustering dimulai dari jumlah cluster sebanyak 2 sampai dengan 6 menggunakan fungsi 'result $=\mathrm{GKC}(\mathrm{X}, \mathrm{U} 0, \mathrm{~m}, \mathrm{e}$, beta, gamma)' pada command window Matlab 2016a. Data yang digunakan adalah Document Term Matrix dengan pembobotan TFIDF.Pangkat fuzzyfier yang digunakan adalah $\mathrm{m}=3,85$ yang merupakan hasil yang paling optimal dari proses trial dan error karena menghasilkan fungsi keanggotaan $u_{i k} \neq 1 / \mathrm{c}$. untuk batas error terkecil dan nilai threshold yang digunakan diambil dari jurnal Babuska (2002) sebesar $\varepsilon=0,001$ dan $\beta=10^{15}$. Sedangkan nilai parameter pembobot yang digunakan sebesar $\gamma=0,8$.

Hasil clustering yang didapat yaitu untuk jumlah cluster sebanyak 4, 5, dan 6 cluster, hanya 3 cluster dari total seluruh cluster yang memiliki anggota kelompok. Jadi, dapat disimpulkan bahwa alamat IP yang mengakses website Universitas Diponegoro pada tanggal 1 November 2019 hingga 7 November 2019 hanya mampu dikelompokkan dengan jumlah cluster maksimal sebanyak 3 cluster. Dalam penelitian ini akan dilakukan analisis terhadap pengelompokkan dengan jumlah cluster 2 dan 3 saja. Hasil clustering dengan jumlah 3 cluster dapat dilihat pada Tabel 5 dan 6 .

Tabel 5. Hasil Clustering dengan Algoritma Gustafson-Kessel untuk jumlah cluster 2

Cluster ke- Kode alamat IP Jumlah

anggota

$\begin{array}{llc}1 & 2,3,6,7,9,10,13,14,15,16,17,20,21,22,23,25, \ldots, 2496 & 1142 \\ 2 & 1,4,5,8,11,12,18,19,24,29,30,31,32,33,37,38, \ldots, 2493 & 1354\end{array}$


Tabel 6. Hasil Clustering dengan Algoritma Gustafson-Kessel untuk jumlah cluster 3

\begin{tabular}{clc}
\hline $\begin{array}{c}\text { Cluster } \\
\text { ke- }\end{array}$ & \multicolumn{1}{c}{ Kode alamat IP } & $\begin{array}{c}\text { Jumlah } \\
\text { anggota }\end{array}$ \\
\hline 1 & $15,45,65,67,132,152,155,250,275,328,347,352,356$, & 96 \\
& $396,467,470,504,506,507,537,560,587,646, \ldots, 2488$ & \\
2 & $344,753,924,1327,1777,1796,1926,1935$ & 8 \\
3 & $1,2,3,4,5,6,7,8,9,10,11,12,13,14,16,17,18,19,20$, & 2392 \\
& $21,22,23,24,25,26,27,28,29,30,31,32,33,34, \ldots, 2496$ & \\
\hline
\end{tabular}

\subsection{Tokenizing}

Tokenizing merupakan proses pemotongan kalimat menjadi kata-kata penyusunnya dengan fungsi yang digunakan pada Rstudio 'unnest_tokens(word, text)'. Tokenizing yang dirancang pada penelitian ini adalah memecah page request dengan white space atau spasi sebagai pembagi.Pada Tabel 7 terlihat contoh tokenizing.

Tabel 7. Contoh Tokenizing

\begin{tabular}{ccc}
\hline Kode alamat IP & Sebelum Tokenizing & Setelah Tokenizing \\
\hline 15 & senat_akademik fakultas fakultas & senat_akademik \\
& fakultas_ilmu_budaya & fakultas \\
& fakultas \\
& fakultas_ilmu_budaya \\
\hline
\end{tabular}

\subsection{Association Rule}

Setelah melakukan clustering, dilakukan asosiasi di setiap cluster yang terbentuk.Proses pembentukan association rule menggunakan fungsi 'apriori(trans, parameter $=\operatorname{list}(\operatorname{supp}=0.04$, conf $=0.04)$ )' pada Rstudio. Support minimum yang digunakan adalah $4 \%$ dan confidence minimum yang digunakan adalah $4 \%$. Nilai ini didapat dari proses trial dan error untuk mendapatkan asosiasi terbaik di setiap cluster. Tabel 8 dan 9 menunjukkan hasil association rule untuk jumlah cluster 3 cluster.

Tabel 8. Hasil Association Rule 2 Cluster

\begin{tabular}{|c|c|c|c|c|c|}
\hline $\begin{array}{c}\text { clust } \\
\text { er }\end{array}$ & LHS & RHS & $\begin{array}{c}\text { Suppor } \\
t\end{array}$ & $\begin{array}{c}\text { Confinde } \\
\text { nce }\end{array}$ & Lift \\
\hline \multirow[t]{9}{*}{1} & $\{$ fakultas $\}$ & $\{$ fakultas_ilmu_sosial_dan_ilmu_politik\} & $6 \%$ & $13 \%$ & 2,3 \\
\hline & $\{$ fakultas $\}$ & \{fakultas_kesehatan_masyarakat $\}$ & $5 \%$ & $100 \%$ & 2,3 \\
\hline & $\{$ fakultas $\}$ & $\{$ fakultas_hukum $\}$ & $5 \%$ & $100 \%$ & 2,3 \\
\hline & $\{$ fakultas $\}$ & $\{$ fakultas_peternakan_dan_pertanian $\}$ & $6 \%$ & $100 \%$ & 2,3 \\
\hline & \{fakultas\} & $\{$ fakultas_teknik $\}$ & $8 \%$ & $17 \%$ & 2,3 \\
\hline & $\{$ fakultas $\}$ & $\{$ fakultas_psikologi $\}$ & $5 \%$ & $13 \%$ & 2,3 \\
\hline & $\{$ fakultas $\}$ & $\{$ fakultas_perikanan_dan_ilmu_kelautan $\}$ & $5 \%$ & $14 \%$ & 2,3 \\
\hline & $\{$ fakultas $\}$ & $\{$ fakultas_ilmu_budaya $\}$ & $6 \%$ & $10 \%$ & 2,3 \\
\hline & $\{$ fakultas $\}$ & \{sekolah_vokasi $\}$ & $5 \%$ & $10 \%$ & 2,3 \\
\hline \multirow[t]{3}{*}{2} & $\{$ penerimaa & \{daya_tampung $\}$ & $5 \%$ & $100 \%$ & 2,3 \\
\hline & $\begin{array}{c}\text { n_mahasisw } \\
\text { a_baru }\}\end{array}$ & & & & \\
\hline & $\{$ fakultas $\}$ & $\{$ fakultas_kedokteran $\}$ & $6 \%$ & $13 \%$ & 2,3 \\
\hline
\end{tabular}


Tabel 9. Hasil Association Rule 3 Cluster

\begin{tabular}{|c|c|c|c|c|c|}
\hline $\begin{array}{c}\text { clust } \\
\text { er }\end{array}$ & $\overline{\text { LHS }}$ & RHS & Support & $\begin{array}{c}\text { Confind } \\
\text { ence }\end{array}$ & Lift \\
\hline \multirow[t]{5}{*}{1} & $\{$ Akademik $\}$ & $\{$ Pindah_studi $\}$ & $10,4 \%$ & $100 \%$ & 7,4 \\
\hline & $\{$ fakultas $\}$ & $\begin{array}{c}\text { \{fakultas_ekonomi_ } \\
\text { dan_bisnis }\end{array}$ & $13,5 \%$ & $24,07 \%$ & 1,8 \\
\hline & $\{$ fakultas $\}$ & $\begin{array}{c}\{\text { fakultas_kedoktera } \\
\mathrm{n}\}\end{array}$ & $26,04 \%$ & $46,30 \%$ & 1,8 \\
\hline & $\{$ fakultas $\}$ & $\{$ sekolah_vokasi\} & $8 \%$ & $15 \%$ & 1,8 \\
\hline & $\{$ fakultas $\}$ & $\begin{array}{c}\{\text { fakultas_ilmu_bud } \\
\text { aya }\}\end{array}$ & $8 \%$ & $15 \%$ & 1,8 \\
\hline \multirow[t]{2}{*}{2} & $\{$ Profil $\}$ & $\begin{array}{c}\text { \{Pimpinan_fakultas } \\
\text { _sains__ } \\
\text { dan_matematika }\}\end{array}$ & $12,5 \%$ & $100 \%$ & 8,0 \\
\hline & $\begin{array}{c}\{\text { Penerimaan_mah } \\
\text { asiswa } \\
\text { _baru }\}\end{array}$ & $\begin{array}{c}\text { \{Kalender_penerim } \\
\text { aan_- } \\
\text { mahasiswa_baru }\}\end{array}$ & $62,5 \%$ & $100 \%$ & 1,6 \\
\hline \multirow[t]{2}{*}{3} & $\begin{array}{c}\{\text { penerimaan_maha } \\
\text { siswa_baru }\}\end{array}$ & \{daya_tampung $\}$ & $5 \%$ & $3,2 \%$ & 6,6 \\
\hline & $\{$ fakultas $\}$ & $\{$ fakultas_teknik\} & $5 \%$ & $10,5 \%$ & 2,3 \\
\hline
\end{tabular}

Pada Tabel 9, setiap cluster memiliki jumlah rules yang berbeda-beda. Nilai support dan confidence dikalikan $100 \%$ untuk mendapatkan hasil dalam bentuk presentase. Lhs menandakan antecendent dan rhs menandakan consequent. Setiap rule yang terbentuk mengartikan bahwa user melakukan akses dari kategori halaman LHS memiliki presentase sejumlah confidence untuk mengakses kategori halaman RHS. Pola tersebut terdapat sejumlah presentase support dari total data dengan nilai lift $>1$ yang menandakan pola tersebut dependent.

\section{KESIMPULAN}

Berdasarkan Metode Gustafson-Kessel Clustering dapat disimpulkan bahwa jumlah cluster yang terbentuk adalah 2 dan 3 cluster.

Dari pengujian yang telah dilakukan pada jumlah cluster 2 terdapat 2 pola user dalam melakukan akses pada website Universitas Diponegoro yang memiliki frekuensi kemunculan tinggi:

Fakultas $\rightarrow$ Fakultas Teknik pada cluster pertama dengan confidence 17\% dan support $6 \%$. Hal tersebut dapat menandakan bahwa sebagian besar user di cluster pertama cenderung melakukan akses dari sub session 'fakultas' menuju sub session 'fakultas teknik'. Artinya pengunjung website di cluster pertama lebih banyak membutuhkan informasi mengenai fakultas teknik.

Penerimaan mahasisw a baru $\rightarrow$ daya tampung pada cluster kedua dengan confidence $13 \%$ dan support 6\%. Hal tersebut dapat menandakan bahwa sebagian besar user di cluster pertama cenderung melakukan akses dari sub session 'penerimaan mahasiswa baru' menuju sub session 'daya tampung'. Artinya pengunjung website di cluster pertama lebih banyak membutuhkan informasi mengenai daya tampung.

Dari pengujian yang telah dilakukan pada jumlah cluster 3 terdapat 3 pola user dalam melakukan akses pada website Universitas Diponegoro yang memiliki frekuensi kemunculan tinggi: 
Fakultas $\rightarrow$ Fakultas Kedokteran pada cluster pertama dengan confidence 46,30\% dan support 26,04\%. Hal tersebut dapat menandakan bahw a sebagian besar user di cluster pertama cenderung melakukan akses dari sub session 'fakultas' menuju sub session 'fakultas kedokteran'. Artinya pengunjung website di cluster pertama lebih banyak membutuhkan informasi mengenai fakultas kedokteran.

Penerimaan mahasiswa baru $\rightarrow$ kalender penerimaan mahasiswa baru pada cluster kedua dengan confidence $100 \%$ dan support $62,5 \%$. Hal tersebut menandakan bahwa sebagian besar pengunjung cenderung melakukan akses dari session 'Penerimaan mahasiswa baru' menuju sub session 'kalender penerimaan mahasiswa baru'. Artinya pengunjung website di cluster kedua membutuhkan informasi mengenai timeline penerimaan mahasiswa baru dari mulai tanggal pelaksanaan hingga tahap seleksi.

Fakultas $\rightarrow$ fakultas teknik pada cluster ketiga dengan confidence 10,5\% dan support $5 \%$. Hal tersebut menandakan sebagian besar user di cluster ketiga cenderung melakukan akses dari session 'fakultas' menuju 'fakultas teknik'. Artinya pengunjung website di cluster ketiga membutuhkan informasi mengenai fakultas teknik.

Beberapa perbaikan yang dapat dilakukan untuk penelitian selanjutnya adalah menggunakan metode clustering yang lebih efisien serta memiliki kecocokan dengan data yang relatif homogen, tahap preprocessing merupakan tahap yang paling penting dan riskan.Pastikan telah dilakukan dengan baik dan seksama, seperti penghapusan page request yang benar-benar tidak dibutuhkan.

\section{DAFTAR PUSTAKA}

Babuska, R., Veen, P.v.d. \& Kaymak, U., 2002.Improved Covariance Estimation for Gustafson-Kessel Clustering. Netherland: Delft University of Technology.

Fauzanu, A., Eko, D. \& Gede, A, A, W., 2017. Analisis Web Usage Mining Menggunakan Teknik K-Means Clustering dan Association Rule (Studi Kasus: www.owlexa.com). e-Proceeding of Engineering, Vol. 4(2), Hal. 3284-3291.

Gustafson, D. \& Kessel, W., 1979, Fuzzy Clustering with a Fuzzy Covariance Matrix. San Diego, Hal. 761-766.

Hikmawan, W. A. 2017. Analisis Web Usage Mining untuk Pembentukan Profil User Menggunakan Algoritma Clustering K-Means (Studi Kasus: Website etd.ugm.ac.id). Universitas Gajah Mada.

Rahmatika, L., Suparti. \&Diah, S., 2015.Analisis Kelompok dengan Algoritma Fuzzy CMeans dan Gustafson Kessel Clustering pada Indeks LQ45.Jurnal Gaussian, Vol. 4(3), Hal. 543-552.

Scime, A., 2004. Web Mining: Applications and Tecniques.USA: State University of New York College at Brockport.

Yan J. (2009) Text Representation. In: LIU L., ÖZSU M.T. (eds) Encyclopedia of Database Systems. Springer, Boston, MA 